\title{
Blood routine risk factors for coronary artery aneurysm in infants younger than 8 months with Kawasaki disease
}

\author{
Ge Haiyan ${ }^{1}$, Lai Jianming ${ }^{2}$, Tong Suqian ${ }^{3}$, Qu Dong ${ }^{1 *}$, Liu Shuang ${ }^{1}$ and Zhang Jin ${ }^{1}$
}

\begin{abstract}
Objective: The aims of this study were to characterize the evolution of routine blood values within the first 10 days of illness and coronary artery outcome in infants $<8$ months with Kawasaki disease (KD) and to identify risk factors for coronary artery aneurysm (CAA).

Methods: Laboratory data, clinical features and coronary artery outcomes from 78 infants $<8$ months old and 86 patients between 8 months and 7 years old were retrospectively analyzed. Logistic regression analysis was conducted to evaluate the potential risk factors for CAA.

Results: Infants $<8$ months old were more likely to present with incomplete KD ( $37.2 \%$ vs $4.7 \%, P<0.001)$, erythema and induration at the BCG inoculation site $(24.4 \%$ vs $3.5 \%, P<0.001)$ and CAA $(47.4 \%$ vs $15.1 \%, P<0.001)$ even with timely diagnosis and treatment with intravenous immunoglobulin (IVIG) compared with patients $\geq 8$ months old. Clinical feature related to diagnostic criteria for KD including bilateral conjunctival injection, oral changes, unilateral cervical lymphadenopathy and extremity changes were less common in the younger group. During the acute phase, the percentage neutrophils and neutrophil to lymphocyte ratio [NLR] peaked on median illness day 3, followed by white blood cell (WBC) and CRP on median illness day 4, hemoglobin on median illness day 7 and platelet count on median illness day 9. CAA occurred on median illness day 6 and regressed on median illness day 28. Multivariate logistic regression analysis revealed that the peak percentage neutrophils (odds ratio [OR] per 0.1: 1.597, 95\% confidence interval [Cl]: 1.041-2.452, $P=0.032$ ) and the peak platelet count (OR per $10 \times 10^{9} / \mathrm{L}: 1.029,95 \% \mathrm{Cl}: 1.004-1.055$, $P=0.024)$ were independent risk factors for CAA. Hemoglobin on the 5 th day was associated with persistent CAA at 1 year after $\mathrm{KD}$ onset.
\end{abstract}

Conclusion: Factors associated with CAA include a high peak percentage neutrophils, increased peak platelet count, and reduced hemoglobin within 4-6 days during the acute phase of KD. Therefore, this population should receive primary therapy with IVIG and adjunctive anti-inflammatory medications.

Keywords: Kawasaki disease, Infants, Coronary artery aneurysm, Routine blood tests

*Correspondence: qudong2012@126.com

1 Department of Critical Care Medicine, Children's Hospital, Capital Institute of Pediatrics, Beijing 100020, China

Full list of author information is available at the end of the article

\begin{abstract}
Introduction
Kawasaki disease (KD) is an acute systemic vasculitis of unknown cause that preferentially affects the coronary artery [1]. The most frequent age at onset of KD ranges from 9 to 11 months, and an onset age younger than 6 months is relatively infrequent [2]. Infants, especially those younger than 6 months, are also reported to have
\end{abstract}


a higher prevalence of incomplete $\mathrm{KD}$, coronary artery aneurysms (CAAs) and adverse cardiac events [3-6]. Acute KD patients at high risk for the development of CAA may benefit from primary therapy with IVIG and adjunctive anti-inflammatory medications, as outlined by the 2017 AHA guidelines [1]. Therefore, early identification of infants with KD at high risk of CAA and the provision of timely primary treatment with adjunctive therapies are very important to improve the prognosis of infants with KD. It has been reported that peripheral blood cell parameters are not only helpful to diagnose incomplete KD but also indicators of the risk of CAA among KD patients $[1,5]$. However, the dynamic change of these laboratory values in infants with KD during the acute phase has rarely been reported. The aims of this study were to characterize the dynamic change of laboratory values within the first 10 days of illness and the coronary artery outcome in infants younger than 8 months with $\mathrm{KD}$, and to describe the use of laboratory data to identify risk factors for coronary aneurysms in this population.

\section{Materials and methods}

We retrospectively enrolled 78 consecutive infants younger than 8 months and 86 patients between 8 months and 7 years who were treated for KD and received intravenous immunoglobulin (IVIG) $(2 \mathrm{~g} / \mathrm{kg} \times 1$ day or $1 \mathrm{~g} /$ $\mathrm{kg} \times 2$ days) therapy within the first 10 days of illness at Children's Hospital, Capital Institute of Pediatrics. Seventy patients were treated at the Department of Critical Care Medicine between October 1, 2015 and December 31,2020 , while the remaining patients were treated at the Department of Rheumatology between March 1, 2019 and December 31, 2020. Patients with congenital heart disease and patients with incomplete data were excluded from the study. We collected clinical data, including age, illness day at diagnosis (illness day $1=$ first day of fever), response to IVIG therapy, complete blood count (white blood cell [WBC] count, percentage neutrophils, percentage lymphocytes, neutrophil to lymphocyte ratio [NLR], hemoglobin, platelet count), plasma concentrations of C-reactive protein (CRP) and coronary artery status. Complete blood count and CRP were collected and analyzed at 2 time points: 1st day (illness days 1-2) and 5th day (illness days 4-6). For patients with multiple laboratory values within a time interval, only the laboratory values on the 1st and 5th days of illness were analyzed. The maximal laboratory value, defined as the highest complete blood count and CRP values at any time point during the first 10 days after fever onset, was also analyzed.

Complete KD was defined as fever $\geq 5$ days and $\geq 4$ of the following clinical signs: Bilateral conjunctival injection, polymorphous skin rash, changes in the lips or oral mucosa, changes (edema/redness/peeling) of the extremities, and unilateral cervical lymphadenopathy. Patients with fever $\geq 5$ days plus $<4$ criteria with or without echocardiogram abnormalities were classified as having incomplete KD. IVIG resistance was defined as recrudescent or persistent fever at least $36 \mathrm{~h}$ after completion of the first IVIG infusion [1]. IVIG-resistant patients were given additional IVIG doses and steroids.

Echocardiography was performed at the time of initial diagnosis and at 1-2 weeks, 3-4weeks and 6-8 weeks after KD onset. In addition, patients with coronary artery damage underwent echocardiograms every one to 3 months depending on the severity of CAA. Patients were classified as having normal $(<2.5$ standard deviations [Z-score] from the mean, normalized for body surface area) or aneurysmal $(Z \geq 2.5)$ coronary arteries on the basis of the maximal internal diameters of the following segments measured by echocardiography during the first 6 weeks after fever onset: Left main coronary artery, proximal and distal left anterior descending artery (LAD), left circumflex, and right coronary artery (RCA) (proximal, middle, and distal). The Z-max was defined as the largest Z-score for any coronary artery segment on each echocardiogram at any time point during the first 6 weeks after fever onset. Persistent CAA was defined as a Z-score of $\geq 2.5$ for the maximal internal diameters of the proximal LAD and proximal RCA on echocardiograms at 12 months after $K D$ onset. CAA regression was defined as a Z-score $<2.5$ on echocardiograms during the follow-up period. Z-scores were calculated using the Dallaire equations (https://www.pedz.de/en/welcome. $\mathrm{html}$ [7]. The study was approved by the regional ethics committee.

\section{Statistical analyses}

All continuous variables are expressed as the mean \pm standard deviation or the median with interquartile range (IQR). The primary comparisons were made between infants $<8$ months old and patients $\geq 8$ months old, and the comparisons of the clinical and laboratory data between infants $<8$ months old with and without CAA were also made. Comparisons between groups were performed with an unpaired Student's t test or MannWhitney $U$ test. Categorical variables are expressed as numbers and percentages and were compared using the chi-square test. After baseline comparisons were performed, the variables that were found to differ between groups were then included in a binary logistic regression analysis to control for their effects. Receiver operating characteristic (ROC) curves and the areas under the curves (AUCs) were constructed to compare the predictive value of laboratory indicators for persistent CAA. 
Statistical analysis was performed using SPSS software (Version 20.0. IBM Corp, Armonk, NY). Statistical significance was defined as $P<0.05$ (two-sided).

\section{Results}

\section{Patient characteristics}

The median age of these patients at the time of diagnosis of acute KD was 0.85 years (IQR: $0.22-2.33$ years), and 96 (58.5\%) were boys. The median duration of fever before the first IVIG treatment was 5 days (IQR: $5-7$ days). Of the patients in this study, $150(91.5 \%)$ received a single course of IVIG treatment, 14 (8.5\%) were IVIG resistant and received IVIG retreatment, and 9 (5.5\%) patients received steroids. Even with timely diagnosis and treatment with IVIG, the incidences of CAA and persistent $\mathrm{CAA}$ at 1 year after $\mathrm{KD}$ onset were $30.5 \%$ (50/164) and $5.5 \%(9 / 164)$, respectively.

Infants $<8$ months old were more likely to have incomplete KD $(37.2 \%$ vs. $4.7 \%, P<0.001)$, erythema and induration at the BCG inoculation site $(24.4 \%$ vs. $3.5 \%$, $\mathrm{P}<0.001)$ and CAA $(47.4 \%$ vs. $15.1 \%, P<0.001)$ compared with patients $\geq 8$ months old. Clinical feature related to diagnostic criteria for KD including bilateral conjunctival injection, oral changes, unilateral cervical lymphadenopathy and extremity changes were less commonly noted in the younger group. No significant difference was found regarding the gender, skin rash, IVIG resistance and persistent CAA at 1 year after KD onset between the two age groups (Table 1 ).

\section{Laboratory data}

Evaluation of the laboratory values by day of illness for the patients with KD showed that the WBC, percentage neutrophils, NLR, hemoglobin, platelet and CRP continued to rise or decline, peaking on different days during the acute phase. Peak values were 17.83 (IQR: 14.30$20.63) \times 10^{9} / \mathrm{L}$ for $\mathrm{WBC}$ on median illness day 4 (IQR: 2-6), 0.73 (IQR: 0.64-0.79) for percentage neutrophils on median illness day 3 (IQR: $2-5$ ), 3.65 (IQR: 2.44-5.60) for NLR on median illness day 3 (IQR: $2-5),(95.2 \pm 13.7)$ $\mathrm{g} / \mathrm{L}$ for hemoglobin on median illness day 7 (IQR: 5-9), 553.0 (IQR: $424.0-715.0) \times 10^{9} / \mathrm{L}$ for platelet count on median illness day 9 (IQR: 8-10), and 73.4 (IQR: 44.0114.0) $\mathrm{mg} / \mathrm{L}$ for CRP on median illness day 4 (IQR: 3-5). In addition, the NLR after initial IVIG administration (median, 2 days after IVIG) was 0.65 (IQR: 0.35-1.31). Infants $<8$ months old had a lower WBC count on the 1st day, percentage neutrophils, NLR, hemoglobin, and a higher platelet count at any time point, compared with patients $\geq 8$ months old. There was no difference in the peak days of any laboratory parameter, WBC count on the 5th day, peak WBC count, and CRP at any time point by age cohort (Table 1 ).

\section{Echocardiography measurements}

During the acute phase of the illness, all of the enrolled patients' electrocardiograms showed normal left ventricular ejection fraction before IVIG. Compared with patients in the older group, a larger proportion of infants $<8$ months old had CAA $(33.3 \%$ Z-score $\geq 2.5$ to $<5,11.5 \% \mathrm{Z}$-score $\geq 5$ to $<10,2.6 \% \mathrm{Z}$-score $\geq 10$ vs. $12.8 \% \mathrm{Z}$-score $\geq 2.5$ to $<5,2.3 \% \mathrm{Z}$-score $\geq 5$ to $<10,0.0 \%$ Z-score $\geq 10, P<0.001)$. CAA occurred on median illness day 6 (IQR: $5-8$, range 1-33). Twenty-five patients (15.2\%) developed CAA in the bilateral coronary arteries, $16(9.8 \%)$ developed CAA in the left coronary artery, and 9 (5.5\%) developed CAA in the RCA. The locations of CAA included the LAD in 28 (17.1\%), the left circumflex in $10(6.1 \%)$, the proximal RCA in $34(20.7 \%)$, the middle RCA in 14 (8.5\%), and the distal RCA in 8 (4.9\%). The median follow-up time for the entire cohort was 510 days (IQR 391-764 days). CAA regression occurred at a median time of 28 days (IQR: $15-115$ days) in 41 patients $(25.0 \%)$. However, nine patients $(5.5 \%)$ including 7 patients $<8$ months old and 2 patients $\geq 8$ months old had persistent CAA at 1 year after KD onset. No significant difference was found regarding the locations of CAA and the incidence of persistent CAA between the two age groups.

\section{Risk factors associated with coronary aneurysms}

Patients with CAA were younger (0.26 [IQR: $0.16-$ 0.81 ] years vs. 1.5 [IQR: $0.38-2.92$ ] years, $P<0.001$ ) and had a higher platelet count on the 1st day $(345.0$ [IQR: $245.0-414.0] \times 10^{9} / \mathrm{L}$ vs. 269.0 [IQR: $230.0-$ $333.0] \times 10^{9} / \mathrm{L}, \quad P=0.009$ ), platelet count on the 5 th day (404 [IQR: $257.5 .0-575.0] \times 10^{9} / \mathrm{L}$ vs. 321.5 [IQR: $\left.268.5-413.5] \times 10^{9} / \mathrm{L}, \quad P=0.033\right)$, peak platelet count (674.0 [IQR: $554.5-877.5] \times 10^{9} / \mathrm{L}$ vs. 501.5 [IQR: 400.0-644.0] $\left.\times 10^{9} / \mathrm{L}, \quad P<0.001\right)$, peak $\quad \mathrm{WBC}$ count (19.57 [IQR: $15.50-24.61] \times 10^{9} / \mathrm{L}$ vs. 17.06 [IQR: $\left.13.92-19.82] \times 10^{9} / \mathrm{L}, P=0.01\right)$, a lower hemoglobin on the 5 th day $(101.06 \pm 17.11 \mathrm{~g} / \mathrm{L}$ vs. $108.30 \pm 14.51 \mathrm{~g} / \mathrm{L}$, $P=0.007)$ and peak hemoglobin $(88.45 \pm 13.08 \mathrm{~g} / \mathrm{L}$ vs. $98.07 \pm 12.93 \mathrm{~g} / \mathrm{L}, \quad P<0.001)$ as compared to patients without CAA. There was no difference in the WBC counts on the 1st and 5th day, percentage neutrophils, NLR and CRP at any time point between patient with and without CAA. Multivariate logistic regression analysis showed that the independent risk factors for CAA were age (odds ratio [OR] per 1 year: $0.630,95 \%$ confidence interval $(\mathrm{CI}): 0.418-0.950, P=0.027)$ and peak platelet count (OR per $10 \times 10^{9} / \mathrm{L}: 1.033$, 95\% CI: $1.012-1.054$, $P=0.002)$.

Table 2 describes the clinical and laboratory data of 37 and 41 infants $<8$ months with CA Z-scores of $\geq 2.5$ 
Table 1 Clinical characteristics of the study population

\begin{tabular}{|c|c|c|c|}
\hline Characteristic & $<8$ months old $(N=78)$ & $\geq 8$ months old $C A(N=86)$ & $P$-value \\
\hline Age (months) & $2.5(1.8 ; 4.6)$ & $27.5(17.0 ; 36.0)$ & $<0.001$ \\
\hline Male sex & $46(59.0 \%)$ & $50(60.5 \%)$ & 0.914 \\
\hline Incomplete KD & $29(37.2 \%)$ & $4(4.7 \%)$ & $<0.001$ \\
\hline Erythema and induration at the BCG inoculation site & $19(24.4 \%)$ & $3(3.5 \%)$ & $<0.001$ \\
\hline Bilateral conjunctival injection, & $57(73.1 \%)$ & $82(95.3 \%)$ & $<0.001$ \\
\hline Oral changes & $60(76.9 \%)$ & $81(94.2 \%)$ & 0.001 \\
\hline Unilateral cervical lymphadenopathy & $52(66.7 \%)$ & $81(94.2 \%)$ & $<0.001$ \\
\hline Extremity changes & $46(59.0 \%)$ & $69(80.2 \%)$ & 0.030 \\
\hline Skin rash & $59(37.2 \%)$ & $66(4.7 \%)$ & 0.868 \\
\hline CAA & $37(47.4 \%)$ & $13(15.1 \%)$ & $<0.001$ \\
\hline Persistent CAA & $7(9.0 \%)$ & $2(2.3 \%)$ & 0.128 \\
\hline Days of fever before IVIG infusion & $5(4 ; 6)$ & $6(5 ; 7)$ & $<0.001$ \\
\hline IVIG resistance & $9(11.5 \%)$ & $5(5.9 \%)$ & 0.191 \\
\hline Peak WBC count $\left(10^{9} / \mathrm{L}\right)$ & $18.16(14.45 ; 23.88)$ & $16.71(14.13 ; 20.0)$ & 0.156 \\
\hline Peak percentage neutrophils & $0.65(0.58 ; 0.74)$ & $0.77(0.70 ; 0.82)$ & $<0.001$ \\
\hline Peak NLR & $2.74(1.85 ; 3.81)$ & $4.61(3.16 ; 6.77)$ & $<0.001$ \\
\hline NLR after IVIG & $0.59(0.32 ; 1.30)$ & $0.70(0.42 ; 1.53)$ & 0.316 \\
\hline Peak hemoglobin (g/L) & $85.95 \pm 10.11$ & $103.44 \pm 10.89$ & $<0.001$ \\
\hline Peak platelet count $\left(10^{9} / \mathrm{L}\right)$ & $693.0(572.0 ; 832.5)$ & $443.5(367.3 ; 538.8)$ & $<0.001$ \\
\hline Peak CRP (mg/L) & $84.0(50.5 ; 113.2)$ & $70.6(35.9 ; 118.4)$ & 0.140 \\
\hline \multicolumn{4}{|l|}{ Laboratory data on the 1st day } \\
\hline WBC count $\left(10^{9} / \mathrm{L}\right)$ & $13.16(9.21 ; 17.05)$ & $14.80(12.44 ; 18.35)$ & 0.028 \\
\hline Percentage neutrophils & $0.62(0.49 ; 0.66)$ & $0.72(0.65 ; 0.80)$ & $<0.001$ \\
\hline NLR & $2.11(1.37: 2.86)$ & $3.53(2.66 ; 5.95)$ & $<0.001$ \\
\hline Hemoglobin (g/L) & $113.00(105.00 ; 126.00)$ & $116.67 \pm 14.62$ & 0.012 \\
\hline Platelet count $\left(10^{9} / \mathrm{L}\right)$ & $336.5(255.5 ; 414.0)$ & $257.0(222.0 ; 315.0)$ & $<0.001$ \\
\hline $\mathrm{CRP}(\mathrm{mg} / \mathrm{L})$ & $39.5(15.5 ; 66.6)$ & $36.0(18.0 ; 56.5)$ & 0.739 \\
\hline \multicolumn{4}{|l|}{ Laboratory data on the 5th day } \\
\hline WBC count $\left(10^{9 / L}\right)$ & $14.08(9.46 ; 18.33)$ & $13.64(10.95 ; 16.39)$ & 0.952 \\
\hline Percentage neutrophils & $0.50(0.34 ; 0.67)$ & $0.70(0.61 ; 0.77)$ & $<0.001$ \\
\hline NLR & $1.38(0.67 ; 2.88)$ & $3.38(2.01 ; 5.30)$ & $<0.001$ \\
\hline Hemoglobin (g/L) & $100.00(88.00 ; 108.00)$ & $113.00(104.50 ; 119.00)$ & $<0.001$ \\
\hline Platelet count $\left(10^{9} / \mathrm{L}\right)$ & $404.0(293.0 ; 566.0)$ & $303.0(257.8 ; 370.0)$ & $<0.001$ \\
\hline $\mathrm{CRP}(\mathrm{mg} / \mathrm{L})$ & $50.0(34.7 ; 96.7)$ & $58.2(28.8 ; 109.0)$ & 0.662 \\
\hline
\end{tabular}

and $<2.5$, respectively, during the acute KD phase. Univariate analysis revealed four potential risk factors associated with CAA, including peak percentage neutrophils, peak NLR, peak platelet count, and WBC count on the 1st day. Multivariate logistic regression analysis was conducted to evaluate the independent effects of the above associated factors on the development of CAA in the younger age group. Peak percentage neutrophils (OR per 0.1: $1.597,95 \% \mathrm{CI}: 1.041-2.452, P=0.032)$ and peak platelet count (OR per $10 \times 10^{9} / \mathrm{L}: 1.029$, 95\% CI: $1.004-$ $1.055, P=0.024)$ were independent risk factors for CAA.

Table 3 shows the clinical and laboratory data of 7 patients with persistent CAA and 71 patients with
Z-scores $<2.5$ at 1 year after $\mathrm{KD}$ onset in the younger group. Univariate analysis revealed two potential risk factors associated with persistent CAA: Hemoglobin on the 5th day and peak hemoglobin. The ROC curve for the prediction of a Z-score $<2.5$ at 1 year after KD onset based on hemoglobin on the 5th day was conducted. The AUC was 0.829 (95\% CI $0.711-0.946, P=0.008$ ). As with the optimal cutoff value of $89.5 \mathrm{~g} / \mathrm{L}$, hemoglobin on the 5 th day had $77.5 \%$ sensitivity ( $83.3 \%$ specificity) for a Z-score $<2.5$ at 1 year after KD onset.

Multivariate logistic regression analysis was also conducted to evaluate the independent effects of peak percentage neutrophils, peak NLR, WBC count on the 1st 
Table 2 Characteristics of infants $<8$ months with and without CAA during the acute phase of KD

\begin{tabular}{|c|c|c|c|}
\hline Characteristic & CAA $(N=37)$ & Normal CA $(N=41)$ & $P$-value \\
\hline Age (months) & $2.4(1.8 ; 3.7)$ & $3.0(2.0 ; 4.9)$ & 0.156 \\
\hline Male sex & $19(51.4 \%)$ & $27(65.9 \%)$ & 0.194 \\
\hline Incomplete KD & $15(40.5 \%)$ & $14(34.1 \%)$ & 0.560 \\
\hline Days of fever before IVIG infusion & $5(4 ; 6)$ & $5(4 ; 6)$ & 0.885 \\
\hline IVIG resistance & $7(18.9 \%)$ & $2(4.9 \%)$ & 0.113 \\
\hline Peak WBC $\left(10^{9} / \mathrm{L}\right)$ & $20.64(15.09 ; 27.52)$ & $17.42(13.40 ; 19.33)$ & 0.052 \\
\hline Peak percentage neutrophils & $0.69 \pm 0.12$ & $0.61 \pm 0.13$ & 0.007 \\
\hline Peak NLR & $3.08(2.37 ; 5.15)$ & $2.46(1.46 ; 3.57)$ & 0.013 \\
\hline NLR after IVIG & $0.58(0.32 ; 1.41)$ & $0.67(0.30 ; 1.24)$ & 0.673 \\
\hline Peak hemoglobin (g/L) & $83.94 \pm 10.26$ & $87.71 \pm 9.77$ & 0.104 \\
\hline Peak platelet count $\left(10^{9} / \mathrm{L}\right)$ & $793.0(576.5 ; 962.5)$ & $659.0(562.0 ; 758.5)$ & 0.015 \\
\hline Peak CRP (mg/L) & $75.5(50.0 ; 135.3)$ & $84.0(59.5 ; 104.7)$ & 0.702 \\
\hline \multicolumn{4}{|l|}{ Laboratory data on the 1st day } \\
\hline WBC count $\left(10^{9} / \mathrm{L}\right)$ & $15.48(10.78 ; 18.66)$ & $12.50(9.00 ; 14.88)$ & 0.045 \\
\hline Percentage neutrophils & $0.61 \pm 0.13$ & $0.55 \pm 0.17$ & 0.113 \\
\hline NLR & $2.11(1.47 ; 3.05)$ & $2.10(1.18 ; 2.75)$ & 0.243 \\
\hline Hemoglobin (g/L) & $116.60 \pm 15.54$ & $115.53 \pm 14.21$ & 0.757 \\
\hline Platelet count $\left(10^{9} / \mathrm{L}\right)$ & $366.2 \pm 146.5$ & $320.2 \pm 97.0$ & 0.106 \\
\hline $\mathrm{CRP}(\mathrm{mg} / \mathrm{L})$ & $43.3(15.3 ; 68.0)$ & $29.0(15.1 ; 61.5)$ & 0.381 \\
\hline \multicolumn{4}{|l|}{ Laboratory data on the 5 th day } \\
\hline WBC count $\left(10^{9 / L}\right)$ & $14.44(9.76 ; 20.33)$ & $12.69(8.73 ; 17.25)$ & 0.070 \\
\hline Percentage neutrophils & $0.55 \pm 0.20$ & $0.47 \pm 0.19$ & 0.095 \\
\hline NLR & $2.03(0.62 ; 3.33)$ & $1.26(0.66 ; 2.00)$ & 0.073 \\
\hline Hemoglobin (g/L) & $97.78 \pm 17.30$ & $101.78 \pm 16.55$ & 0.303 \\
\hline Platelet count $\left(10^{9} / \mathrm{L}\right)$ & $452.7 \pm 200.6$ & $398.3 \pm 143.8$ & 0.172 \\
\hline $\mathrm{CRP}(\mathrm{mg} / \mathrm{L})$ & $45.85(33.5 ; 96.5)$ & $59.0(36.8 ; 98.0)$ & 0.614 \\
\hline
\end{tabular}

day and variables that differed between groups with and without CAA on the development of CAA in the older age group. Peak platelet count (OR per $10 \times 109 / \mathrm{L}: 1.046$, 95\% CI: $1.002-1.092, P=0.042)$ was an independent risk factors for CAA.

\section{Discussion}

The data of this study showed that $37.2 \%$ of infants younger than 8 months had incomplete KD, $47.4 \%$ of these infants had CAA, and 9.0\% had persistent CAA at 1 year after $\mathrm{KD}$ onset. Consistent with the results described in this study, Salgado et al. [4] found that infants $<6$ months old with acute KD are more likely to present with incomplete $\mathrm{KD}$ and develop CAA despite timely treatment with IVIG within the first 10 days. As KD is a form of systemic vasculitis, it may lead to dynamic changes in peripheral blood cells, characterized by an elevated WBC count, percentage neutrophils, platelet count, and anemia over time [8]. As CAA most often occurs within 8 days after the onset of fever [9], we focused on the dynamic nature of peripheral blood cells over 10 days and found that WBC, percentage neutrophils, platelet count and hemoglobin peaked on different days after KD onset, suggesting that peripheral blood cell parameters played significantly different roles in the dynamic process of KD inflammation. Further, we also found that peak percentage neutrophils was significantly associated with the risk of CAA in infants younger than 8 months, which was not suitable for patients $\geq 8$ months old. Last, another finding was that hemoglobin on the 5th day was closely related to persistent CAA.

These data showed that the median peaks of WBC and percentage neutrophils were at 3-5 days of illness onset. Furthermore, the peak percentage neutrophils was an independent predictor of CAA. Previous studies showed that the number of circulating functionally activated neutrophils increased and produced excessive reactive oxygen species and elastase, which may contribute to the formation of coronary artery lesions in patients with KD during the acute phase [10,11]. Takahashi et al. [12] also reported that numerous neutrophils were identified in the coronary artery lesions of patients who died 10 days after KD onset, and these high numbers of neutrophils 
Table 3 Characteristics of infants $<8$ months with and without persistent CAA at 1 year after KD onset

\begin{tabular}{|c|c|c|c|}
\hline Characteristic & Persistent CAA $(N=7)$ & Normal CA $(N=71)$ & $P$-value \\
\hline Age (months) & $2.5(1.8 ; 3.6)$ & $2.5(1.8 ; 4.7)$ & 0.820 \\
\hline Male sex & $3(42.9 \%)$ & $43(60.5 \%)$ & 0.613 \\
\hline Incomplete KD & $3(42.9 \%)$ & $26(36.6 \%)$ & 1.000 \\
\hline Days of fever before IVIG infusion & $5(4 ; 10)$ & $5(4 ; 6)$ & 0.323 \\
\hline IVIG resistance & $2(28.6 \%)$ & $7(9.9 \%)$ & 0.391 \\
\hline Peak WBC count $\left(10^{9} / \mathrm{L}\right)$ & $19.79(15.26 ; 39.29)$ & $18.16(14.44 ; 23.73)$ & 0.392 \\
\hline Peak percentage neutrophils & $0.73 \pm 0.12$ & $0.64 \pm 0.13$ & 0.138 \\
\hline Peak NLR & $3.41(2.53 ; 9.11)$ & $2.68(1.71 ; 3.80)$ & 0.174 \\
\hline NLR after IVIG & $0.60(0.30 ; 2.57)$ & $0.59(0.31 ; 1.28)$ & 0.893 \\
\hline Peak hemoglobin (g/L) & $77.83 \pm 9.06$ & $86.63 \pm 9.95$ & 0.040 \\
\hline Peak platelet count $\left(10^{9} / \mathrm{L}\right)$ & $785.7 \pm 112.4$ & $706.7 \pm 221.5$ & 0.392 \\
\hline Peak CRP (mg/L) & $125.5(51.8 ; 162.5)$ & $82.0(50.0 ; 110.0)$ & 0.100 \\
\hline \multicolumn{4}{|l|}{ Laboratory data on the 1st day } \\
\hline WBC count $\left(10^{9} / \mathrm{L}\right)$ & $16.58(11.81 ; 19.36)$ & $13.13(9.05 ; 16.83)$ & 0.184 \\
\hline Percentage neutrophils & $0.63 \pm 0.17$ & $0.57 \pm 0.15$ & 0.456 \\
\hline NLR & $2.76(1.45: 4.43)$ & $2.04(1.35 ; 2.86)$ & 0.350 \\
\hline Hemoglobin (g/L) & $108.67 \pm 15.67$ & $116.67 \pm 14.62$ & 0.205 \\
\hline Platelet count $\left(10^{9} / \mathrm{L}\right)$ & $364.7 \pm 115.5$ & $339.4 \pm 124.8$ & 0.634 \\
\hline $\mathrm{CRP}(\mathrm{mg} / \mathrm{L})$ & $46.00(14.0 ; 86.2)$ & $37.0(15.7 ; 64.8)$ & 0.700 \\
\hline \multicolumn{4}{|l|}{ Laboratory data on the 5 th day } \\
\hline WBC count $\left(10^{9 / L}\right)$ & $14.52(8.84 ; 17.42)$ & $14.08(9.46 ; 18.50)$ & 0.992 \\
\hline Percentage neutrophils & $0.52 \pm 0.24$ & $0.50 \pm 0.20$ & 0.837 \\
\hline NLR & $2.18(0.50 ; 4.63)$ & $1.37(0.66 ; 2.77)$ & 0.610 \\
\hline Hemoglobin (g/L) & $83.50 \pm 9.61$ & $101.230 \pm 16.70$ & 0.012 \\
\hline Platelet count $\left(10^{9} / \mathrm{L}\right)$ & $424.0 \pm 284.7$ & $423.7 \pm 164.2$ & 0.997 \\
\hline $\mathrm{CRP}(\mathrm{mg} / \mathrm{L})$ & $82.3(46.3 ; 125.8)$ & $47.1(34.4 ; 95.5)$ & 0.215 \\
\hline
\end{tabular}

were involved in the initial damage to the coronary artery during the acute phase of KD. Ha et al. [13] reported that KD patients with CAA had a higher acute NLR than patients without CAA, and we also found a significant difference in the peak NLR between infants younger than 8 months with and without CAA in this study. Therefore, the domination of leukocytes by neutrophils plays an important role during the early stage of KD and is significantly associated with the risk of CAA.

In this study, the platelet count peaked within 8-10 days of illness and had independent predictive value for CAA. This was consistent with the findings of Ueno et al. [14], who reported that platelet-neutrophil aggregates were significantly associated with pathological developments of CAA in KD. During the acute phase of KD, coronary artery injury leads to increased platelet activation and an increase in platelet-neutrophil aggregates, resulting in amplified vascular inflammation and tissue injury. Prednisolone could inhibit platelet-neutrophil aggregate-induced amplified vascular inflammatory activation $[14,15]$. Therefore, platelets had an important effect on coronary vascular inflammation after initial neutrophil infiltration, especially on illness days $8-10$, and were predictive of CAA development.

Another significant finding in our study was that the median illness day of the lowest hemoglobin level was 7 and that hemoglobin on the 5th day was closely related to persistent CAA at 1 year after KD onset. Kosaka et al. [16] also found that lower acute age-adjusted hemoglobin levels were correlated with the risk of coronary dilation in patients with incomplete KD. Tremoulet et al. [8] revealed that anemia was normocytically normochromic and resolved spontaneously over a period of 6 weeks. Previous studies demonstrated that anemia of inflammation caused by iron sequestration and impaired erythropoiesis in the setting of acute or chronic inflammation was an independent predictor of increased mortality in critically ill patients [17-19]. Hence, the lower the hemoglobin level is in the acute phase of KD, the more severe the coronary artery damage will be. Hemoglobin during the acute phase, especially on the 5th day, can be used for risk stratification in infants with $\mathrm{KD}$.

There are some limitations to our study. This was a singlecenter retrospective study. Therefore, further multicenter 
studies with adequate sample sizes are warranted to assess the generalizability of these findings. In addition, we analyzed only blood cell counts and CRP as other laboratory values were not available for all 2 selected time points. Nevertheless, the laboratory markers we analyzed in this study are the most readily available and inexpensive parameters. Last, the acute phase treatment was not standardized, and the coronary Z-score was not based on the normal value for Chinese children.

In conclusion, incomplete KD and CAA occurred frequently in infants. Peak percentage neutrophils within $2-5$ days of illness and peak platelet count within 8-10days of illness were significantly associated with the risk of CAA. Hemoglobin within 4-6 days was associated with persistent CAA and may be used as a predictor of persistent CAA due to KD in infants. For infants with high peak percentage neutrophils within $2-5$ days of illness, the use of steroids, cyclosporine, or infliximab in combination with initial IVIG should be considered in the early stages of KD.

\section{Authors' contributions}

$\mathrm{DQ}$ and $\mathrm{HG}$ initially conceptualized this study. All of the authors performed the data acquisition and analysis. DQ and HG wrote the manuscript. All of the authors read and approved the final manuscript.

\section{Funding}

The Special Fund of the Pediatric Medical Coordinated Development Center of Beijing Hospitals Authority. NO. XTCX201820, NO. XTZD20180504.

\section{Availability of data and materials}

The datasets used and analysed during the current study available from the corresponding author on reasonable request.

\section{Declarations}

\section{Ethics approval and consent to participate}

The study has been approved and granted an exemption from requiring informed consent by the regional ethics committee of the Capital Institute of Pediatrics (SHERLLM2021004). The study has been performed in accordance with the Declaration of Helsinki.

\section{Consent for publication}

Not applicable.

\section{Competing interests}

The authors declare that they have no conflicts of interest/competing interests.

\section{Author details \\ 'Department of Critical Care Medicine, Children's Hospital, Capital Institute of Pediatrics, Beijing 100020, China. ${ }^{2}$ Department of Rheumatology, Children's Hospital, Capital Institute of Pediatrics, Beijing 100020, China. ${ }^{3}$ Department of Cardiology, Guiyang Children's Hospital, Guiyang Maternal and Child Health Hospital, Guiyang 550003, Guizhou Province, China.}

Received: 28 May 2021 Accepted: 15 December 2021

Published online: 07 January 2022

\section{References}

1. McCrindle BW, Rowley AH, Newburger JW, et al. Diagnosis, treatment, and long-term Management of Kawasaki Disease: a scientific statement for health professionals from the American Heart Association. Circulation. 2017;135(17):e927-99. https://doi.org/10.1161/CIR.00000 00000000484 PMID: 28356445.

2. Makino N, Nakamura Y, Yashiro M, et al. Epidemiological observations of Kawasaki disease in Japan, 2013-2014. Pediatr Int. 2018;60(6):581-7. https://doi.org/10.1111/ped.13544 PMID: 29498791.

3. Moreno E, Garcia SD, Bainto E, et al. Presentation and outcomes of Kawasaki disease in Latin American infants younger than 6 months of age: a multinational multicenter study of the REKAMLATINA network. Front Pediatr. 2020;8:384. https://doi.org/10.3389/fped.2020.00384 PMID: 32766186.

4. Salgado AP, Ashouri N, Berry EK, et al. High risk of coronary artery aneurysms in infants younger than 6 months of age with Kawasaki disease. J Pediatr. 2017;185:112-116.e1. https://doi.org/10.1016/j.jpeds.2017.03. 025 PMID: 28408126

5. Nakamura Y, Yashiro M, Uehara R, et al. Use of laboratory data to identify risk factors of giant coronary aneurysms due to Kawasaki disease. Pediatr Int. 2004;46(1):33-8. https://doi.org/10.1111/j.1442-200X.2004. 01840.x PMID: 15043662.

6. Friedman KG, Gauvreau K, Hamaoka-Okamoto A, et al. Coronary artery aneurysms in Kawasaki disease: risk factors for progressive disease and adverse cardiac events in the US population. J Am Heart Assoc. 2016;5(9):e003289. https://doi.org/10.1161/JAHA.116.003289 PMID: 27633390.

7. Dallaire F, Dahdah N. New equations and a critical appraisal of coronary artery Z scores in healthy children. J Am Soc Echocardiogr. 2011;24(1):60-74. https://doi.org/10.1016/j.echo.2010.10.004 PMID: 21074965.

8. Tremoulet AH, Jain S, Chandrasekar D, Sun X, Sato Y, Burns JC. Evolution of laboratory values in patients with Kawasaki disease. Pediatr Infect Dis J. 2011;30(12):1022-6. https://doi.org/10.1097/INF.0b013e3182 2d4f56 PMID: 21817952.

9. Takahashi K, Oharaseki T, Yokouchi Y. Histopathological aspects of cardiovascular lesions in Kawasaki disease. Int J Rheum Dis. 2018;21 (1):315. https://doi.org/10.1111/1756-185X.13207 PMID: 29105353.

10. Yoshimura K, Tatsumi K, Iharada A, et al. Increased nitric oxide production by neutrophils in early stage of Kawasaki disease. Eur J Pediatr. 2009;168(9):1037-41. https://doi.org/10.1007/s00431-008-0872-1 PMID: 19020897.

11. Biezeveld MH, van Mierlo G, Lutter R, et al. Sustained activation of neutrophils in the course of Kawasaki disease: an association with matrix metalloproteinases. Clin Exp Immunol. 2005;141 (1):183-8. https://doi. org/10.1111/j.1365-2249.2005.02829.x PMID: 15958085.

12. Takahashi K, Oharaseki T, Naoe S, Wakayama M, Yokouchi Y. Neutrophilic involvement in the damage to coronary arteries in acute stage of Kawasaki disease. Pediatr Int. 2005;47(3):305-10. https://doi.org/10. 1111/j.1442-200x.2005.02049.x PMID: 15910456.

13. Ha KS, Lee J, Jang GY, et al. Value of neutrophil-lymphocyte ratio in predicting outcomes in Kawasaki disease. Am J Cardiol. 2015;1 16(2):301-6. https://doi.org/10.1016/j.amjcard.2015.04.021 PMID: 25975725.

14. Ueno K, Nomura Y, Morita Y, Eguchi T, Masuda K, Kawano Y. Circulating platelet-neutrophil aggregates play a significant role in Kawasaki disease. Circ J. 2015;79(6):1349-56. https://doi.org/10.1253/circj.CJ-141323 PMID: 25787672.

15. Kobayashi T, Saji T, Otani T, et al. Efficacy of immunoglobulin plus prednisolone for prevention of coronary artery abnormalities in severe Kawasaki disease (RAISE study): a randomised, open-label, blindedendpoints trial. Lancet. 2012;379(9826):1613-20. https://doi.org/10. 1016/S0140-6736(11)61930-2 PMID: 22405251.

16. Ha KS, Jang GY, Lee J, Lee KC, Son CS. Laboratory markers in incomplete Kawasaki disease according to coronary artery outcome. Korean Circ J. 2018;48(4):287-95. https://doi.org/10.4070/kcj.2017.0342 PMID: 29625511.

17. Corwin HL, Gettinger A, Pearl RG, et al. The CRIT study: anemia and blood transfusion in the critically ill--current clinical practice in the United States. Crit Care Med. 2004;32(1):39-52. https://doi.org/10. 1097/01.CCM.0000104112.34142.79 PMID: 14707558. 
18. Macciò A, Madeddu C, Gramignano G, et al. The role of inflammation, iron, and nutritional status in cancer-related anemia: results of a large, prospective, observational study. Haematologica. 2015;100(1):124-32 https://doi.org/10.3324/haematol.2014.112813 PMID: 25239265.

19. Fraenkel PG. Anemia of inflammation: a review. Med Clin North Am. 2017;101 (2):285-96. https://doi.org/10.1016/j.mcna.2016.09.005 PMID: 28189171.

\section{Publisher's Note}

Springer Nature remains neutral with regard to jurisdictional claims in published maps and institutional affiliations.

- fast, convenient online submission

- thorough peer review by experienced researchers in your field

- rapid publication on acceptance

- support for research data, including large and complex data types

- gold Open Access which fosters wider collaboration and increased citations

- maximum visibility for your research: over $100 \mathrm{M}$ website views per year

At BMC, research is always in progress.

Learn more biomedcentral.com/submissions 